Document downloaded from:

http://hdl.handle.net/10251/94476

This paper must be cited as:

Bloem, C.; Salvador Moya, MD.; Amigó, V.; Vicente-Escuder, A. (2009). Fatigue behaviour of GMAW welded aluminium alloy AA7020. Welding International. 23(10):111-116. doi:10.1080/09507110902843321

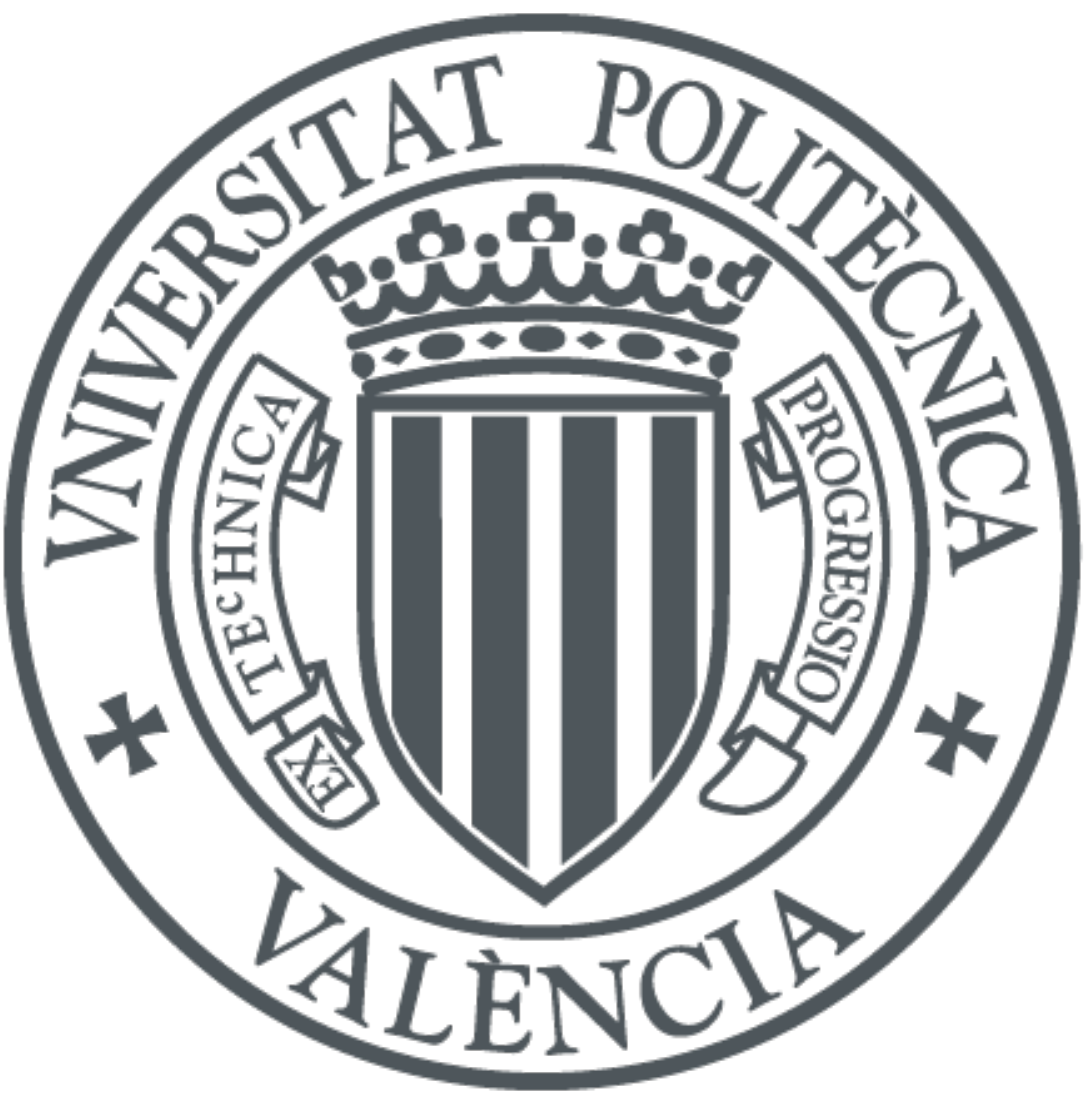

The final publication is available at

http://doi.org/10.1080/09507110902843321

Copyright Taylor \& Francis

Additional Information 


\title{
Fatigue behaviour of GMAW welded aluminium alloy AA7020
}

\author{
C.A. Bloem ${ }^{\mathrm{a} 1}$, M.D. Salvador ${ }^{\mathrm{b}}$, V. Amigó ${ }^{\mathrm{b}}$ and A. Vicente $^{\mathrm{b}}$ \\ ${ }^{a}$ Department of Design and Technology, Faculty of Engineering, School of Mechanical \\ Engineering, Universidad de Los Andes, Mérida, Edo, Mérida, Venezuela; \\ ${ }^{b}$ Department of Mechanical Engineering and Materials, ETSII, Universidad Politécnica \\ de Valencia, Camino de Vera S/N, 46022 Valencia, Spain
}

\begin{abstract}
The aim of this investigation is to evaluate the influence on fatigue behaviour of the finishing of the bulge in a welded aluminium-zinc-magnesium alloy AA7020. It was determined that total or partial elimination of the bulge has very little influence on its behaviour, giving a very similar result on both cases, where one is better than the other by only $3 \%$.
\end{abstract}

Keywords: aluminium alloys; MIG welding; fatigue

\section{Introduction}

Aluminium is being used ever more widely, including in large structures, constructions that, in one way or the other, require assembly or fastening methods. Of these procedures, welding is perhaps the most commonly used joining method and the reason for this is based on the fact that it is the most reliable, safe, economic and easily executed joining method. Of the different welding methods, it is undoubtedly the process of gas metal arc welding, GMAW (MIG) that is most commonly used due to its versatility, safety, ease, excellent quality, low cost and the advantage of the absence of fluxes and/or solid shields, which, in the long term, can be prejudicial to the quality of the welded join ${ }^{1}$.

It is well known that the aging aluminium alloys owe their good behaviour to the quality and level of the precipitates within the matrix ${ }^{2-5}$, which is the basic reason why welded joints of these aluminiums lose much of their mechanical properties ${ }^{1,2,6-8}$. The microstructural evolution along the heat-affected zone (HAZ) has been sufficiently described in these alloys, both under laboratory conditions ${ }^{9}$ and in their industrial application ${ }^{10}$.

There have been many studies of the effect produced on mechanical behaviour by the surface finishing of the welded joint ${ }^{11-13}$. However, these investigations have for the most part been carried out under laboratory conditions and not related to the variables of industrial use. It is known that the surface finishing plays a decisive part in mechanical behaviour, however, the studies carried out have been based on the use of welding as is, comparing it with a mirror finish ${ }^{14}$. In other cases, the use of grit blasting as a means of increasing the resistance and lifespan of welded joints has been evaluated ${ }^{12,15,16}$, however, in industrial use the welding is either left as is, or at best is polished using emery.

2. Experimental procedure

2.1 Materials 
For the production of the test pieces, an alloy of the Al-Zn-Mg family was used, AA7020, provided by ALUMAFEL in sheets of 5mm thickness, in state T6, whose composition is given in Table 1. The filler metal used (see Table 1) corresponds to an AA 5356 alloy, in the form of a wire, with a diameter of $1.2 \mathrm{~mm}$.

Table 1. Chemical composition of filler and base metal.

\begin{tabular}{lccccc}
\hline Alloy & $\mathrm{Mg}$ & $\mathrm{Si}$ & $\mathrm{Cr}$ & $\mathrm{Mn}$ & $\mathrm{Zn}$ \\
\hline Base AA 7020 & 1.20 & 0.17 & 0.31 & 0.20 & 5.05 \\
Filler AA 5356 & 5.00 & & 0.12 & 0.15 & 0.10 \\
\hline
\end{tabular}

Finally, a mixture of argon and helium in a 3:1 ratio, and with a flow of $12 \mathrm{l} / \mathrm{min}$, was used as shielding gas.

\subsection{Welding process}

With the aim of evaluating the effect produced on the quality of the welded joint by surface finishing, four plates were welded, two for each variable. The dimensions of the plates before welding were $350 \times 150 \times 5 \mathrm{~mm}$ and they were extracted from the same sheet and welded in the perpendicular direction to the laminating direction, along the $350 \mathrm{~mm}$ length.

The plates were fixed to a pair of trestles with the aim of maintaining the distance and parallel positioning between them during the welding process.

The cleaning of the joints to be welded was achieved by means of a gentle wiping with an abrasive disc, maintaining the joint morphology as much as possible.

The welds were carried out in two passes, with a mechanical cleaning with abrasive disk and inspection by means of penetrating liquid between the first and second pass. The welding conditions are provided in Table $2^{10}$.

Table 2. Welding conditions.

\begin{tabular}{lcccc}
\hline Pass & $V(\mathrm{~V})$ & $I(\mathrm{~A})$ & Speed $(\mathrm{mm} / \mathrm{min})$ & GEI $(\mathrm{kJ} / \mathrm{cm})$ \\
\hline First & 21.0 & 140 & 525 & 5.6 \\
Second & & & 382 & 7.7 \\
\hline
\end{tabular}

In one case, the bulge was completely eliminated using an abrasive grinder and, in the other, it was only smoothed, with the aim of softening the edges of the welded joint and to provide a uniform welded surface, that is, to eliminate the roughness in the welded zone and the HAZ, thereby using variables of industrial use with the aim of obtaining results closer to the technological reality.

The quality of the weld was evaluated by means of visual inspection, penetrating liquids before and after elimination or retouching of the bulge and, finally, by X-ray, discounting any samples that showed defects, as may be seen in Figure 1 where one of the X-rays carried out may be seen. 


\section{[IING2]}

\section{T6S2 IIIHITा}

Figure 1. Welded join X-ray.

\subsection{Metallographic study}

Test pieces were prepared for optical and scanning electron microscopy of the crosssection of the bead and the HAZ, with the aim of evaluating the size, shape, morphology and other micro-structural characteristics of the bead and the base metalbead interface. In the same way, quantitative energy dispersive X-ray (EDX) analyses were carried out, using the microprobe from Oxford Instruments Ltd, in the vicinity of the base metal-bead interface.

The microstructure of the joint and the distribution of the precipitates were observed using an optical Microphot FX microscope from Nikon and a JSM6300 scanning electron microscope from JEOL. Finally, the evolution of the precipitates along the weld bead and the HAZ was studied using the EM400 transmission electron microscope from Phillips, using the clear field technique.

\subsection{Mechanical characterization}

Traction tests were carried out in accordance with the ASTM E-8m standard, at a load speed of $5 \mathrm{~mm} / \mathrm{min}$, in an Instron 4204 universal testing machine. The four-point bending fatigue tests were carried out on a fatigue testing bank designed for this purpose. The reason for using the four-point bending test was based on the possibility of exercising traction and compression loads, homogeneously distributed along the HAZ, during the tests, using a force ratio $\mathrm{R}=-0.1$.

\section{Results and discussion}

Although it may be intuited that the fact of leaving a part of the bulge might have a decisive influence on fatigue behaviour, perceptibly decreasing the fatigue life by itself being a concentrator of forces, it might be beneficial in the static response of the welded joint, by providing a greater effective area in the zone of the joint and, consequently, the need to analyse the effect of its elimination on the static and dynamic behaviour of the joint. 
In Figure 2 are shown the average results obtained from the different traction tests carried out. Here, it can be seen that the effect of leaving the bulge decisively affects the static behaviour of the joint, since it is directly responsible for a greater staticmechanical resistance, since, as is known, the filler material used in these aluminium alloys possesses lower mechanical resistance than the base metal.

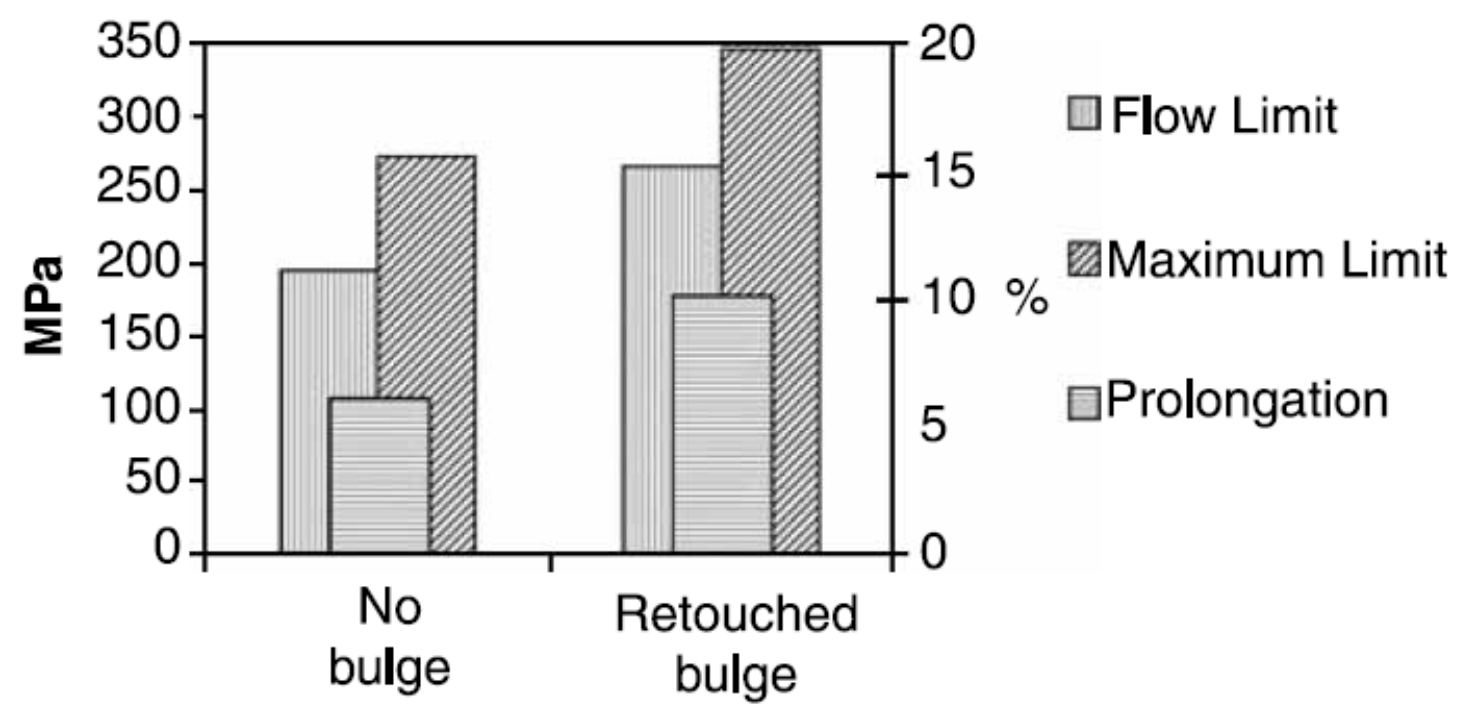

Figure 2. Static mechanical behaviour.

When part of the bulge was left on these test pieces, it generates a better effective crosssection and consequently reduces the real stress on this region, with the bulge therefore being responsible for this better static response. In addition, the microstructure of the bead zone was evaluated, with the observation that, as a result of the welding process itself, a series of micropores appears in the vicinity of the limit between the two beads applied, as well as in the centre of these, as can be seen in Figure 3.

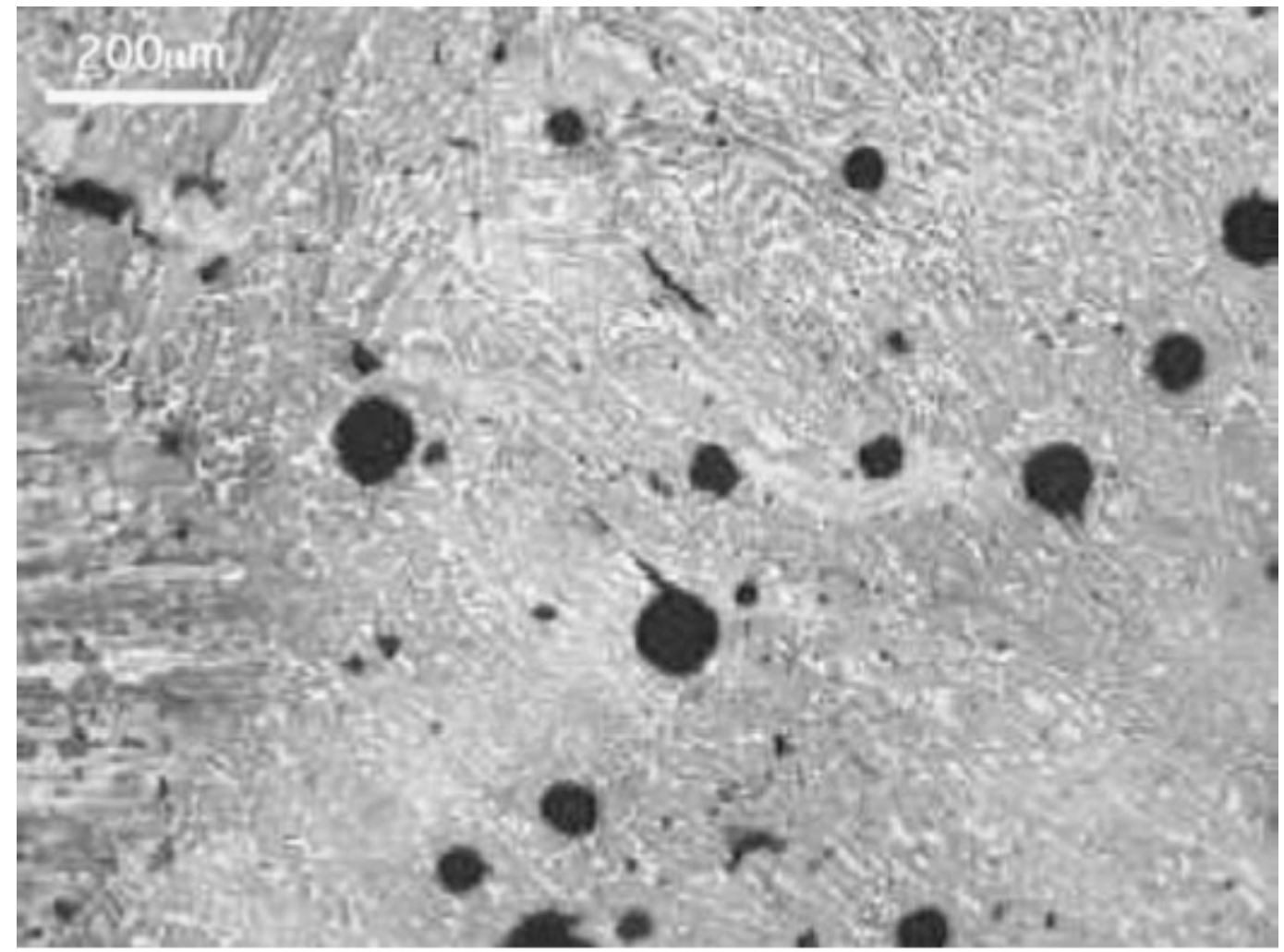


Figure 3. Photograph of base-metal weld interface. Weck etching.

From the analysis of the EDX analyses in the centre of the bead, a small dilution in the alloying metals from the base metal to the bead can be seen, as previously described ${ }^{17}$ and, where it is indicated that this dilution generates a new $\mathrm{Al}-\mathrm{Zn}-\mathrm{Mg}$ alloy with a much lower zinc content than the base metal, but with a slight contribution to the hardening of the bead.

The microstructural evolution along the HAZ, as described by Bloem et al. ${ }^{10,17}$ and Su et al. ${ }^{18}$ shows a heterogeneity both in the level and the quality of the precipitates.

However, in all cases, the hardening mechanism remains the same and, consequently, any change in the mechanical response between these joins will result from the bulge variables. In Figure 4, this mechanism for hardening by means of anchoring of the dislocations between the precipitations can be seen.

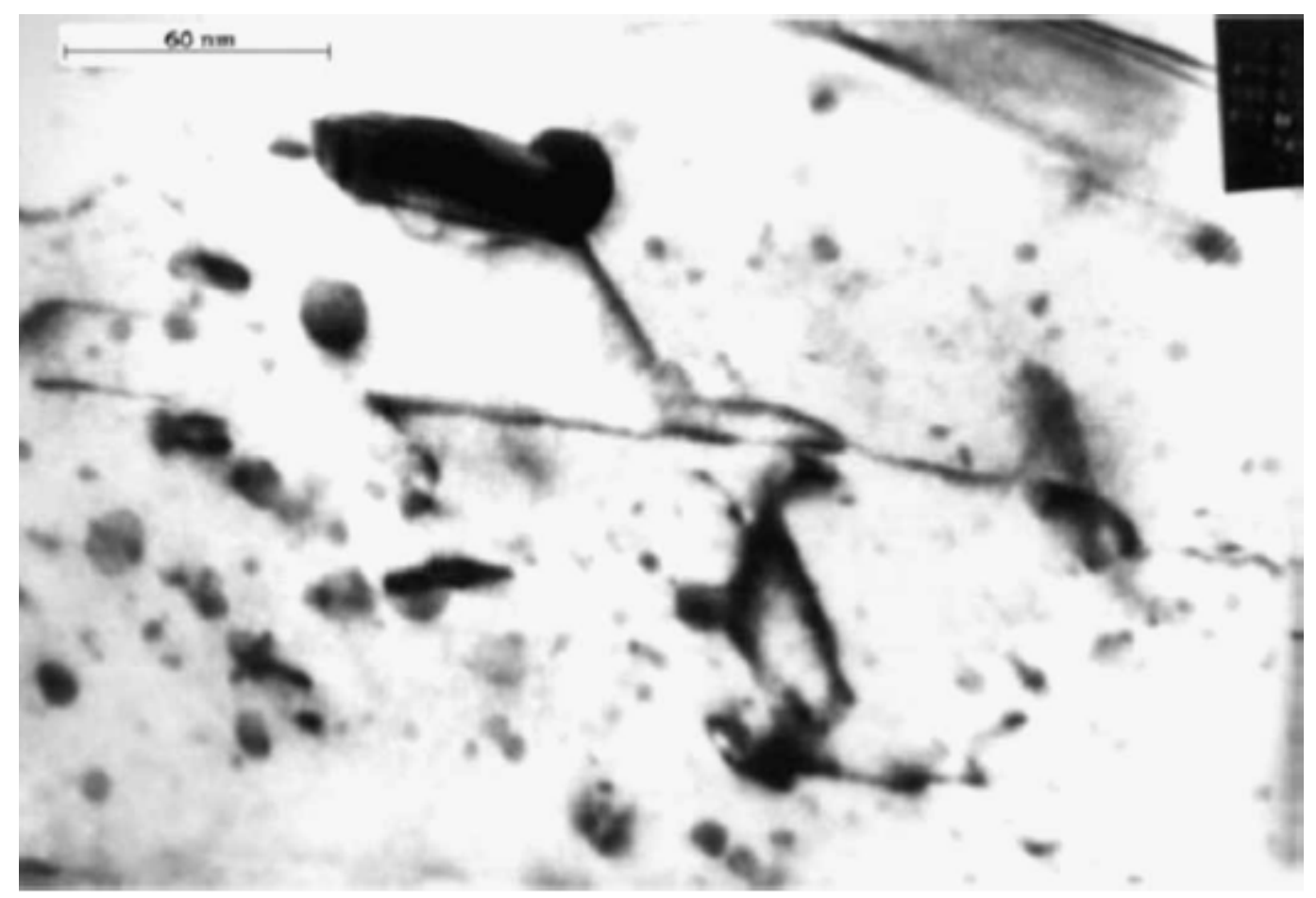

Figure 4. HAZ Micrography 165,000X.

As shown in Figures 3 and 5, despite the joints having been X-rayed, a significant volume of microporosity exists that, eventually, together with the stress concentrators and the surface roughness, may have repercussions for the fatigue behaviour of the joint. This porosity, almost spherical in nature, indicates that it is due to the detachment of hydrogen, the product of small quantities of grease or organic solvent in the joint ${ }^{17}$. However, the level of porosity is similar in all cases and consequently should have the same repercussions in both conditions. In Figure 5, a fatigue crack surface can be seen, where the crack changes direction and speed upon encountering one of these pores. 


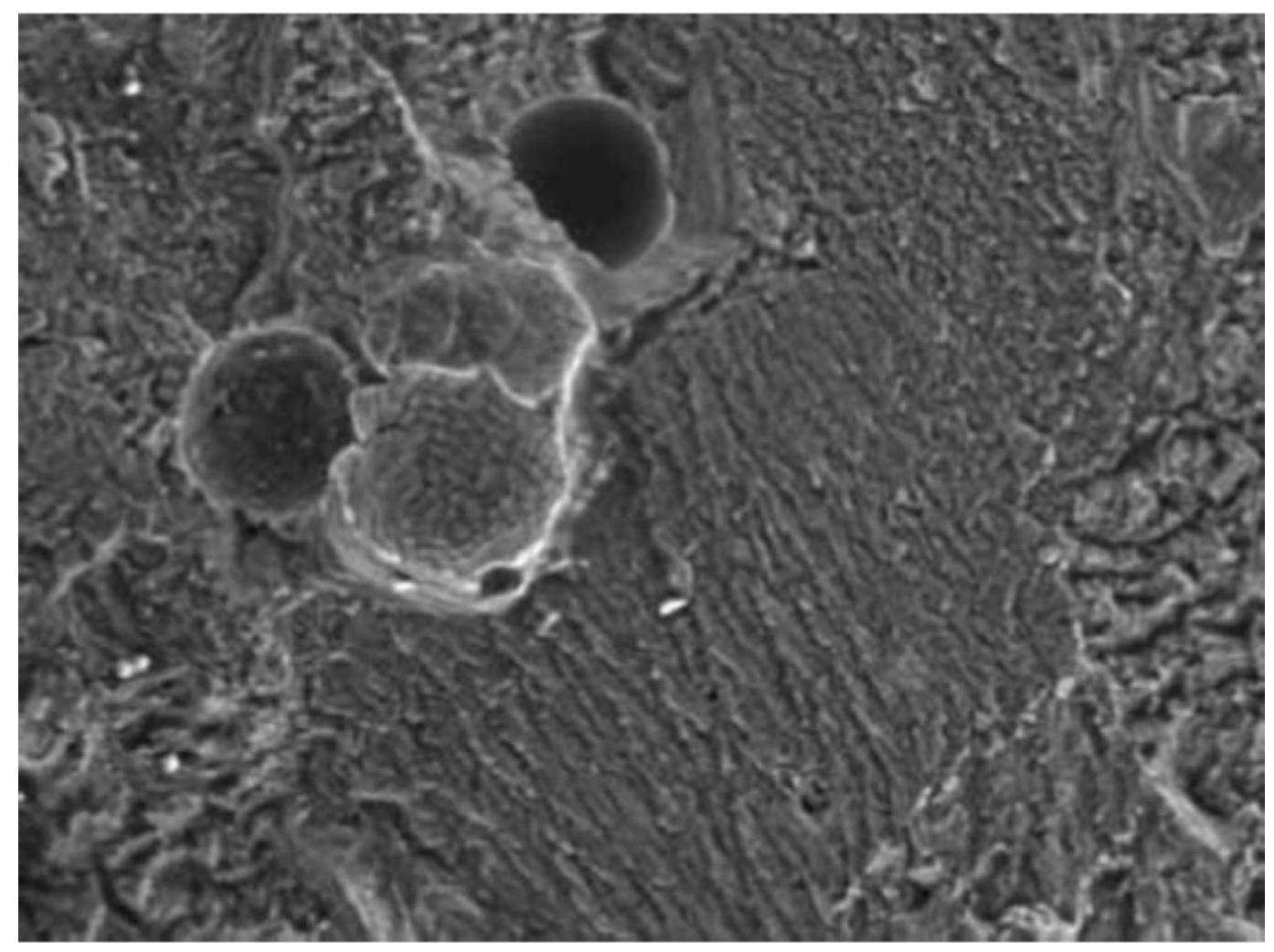

Figure 5. Fatigue fractography in the welded zone. 250X.

The average diameter of the pores present in the different welded joints is between 30 and $50 \mathrm{~mm}$, as shown in Figure 6 . Here, it is possible to see the average porosity level in three different zones of the weld. As can be seen, it is in the centre of the weld bead that the greatest average size of the pores is to be found, which may be attributed to the inability of the gases to escape. These results correspond with those obtained by Lefebvre et al. ${ }^{19}$, who not only evaluated the size, but also evaluated the morphology of the pores. However, this porosity is similar for both of the conditions analysed and hence any change in the response of the join must basically be due to the morphology of the bead. 


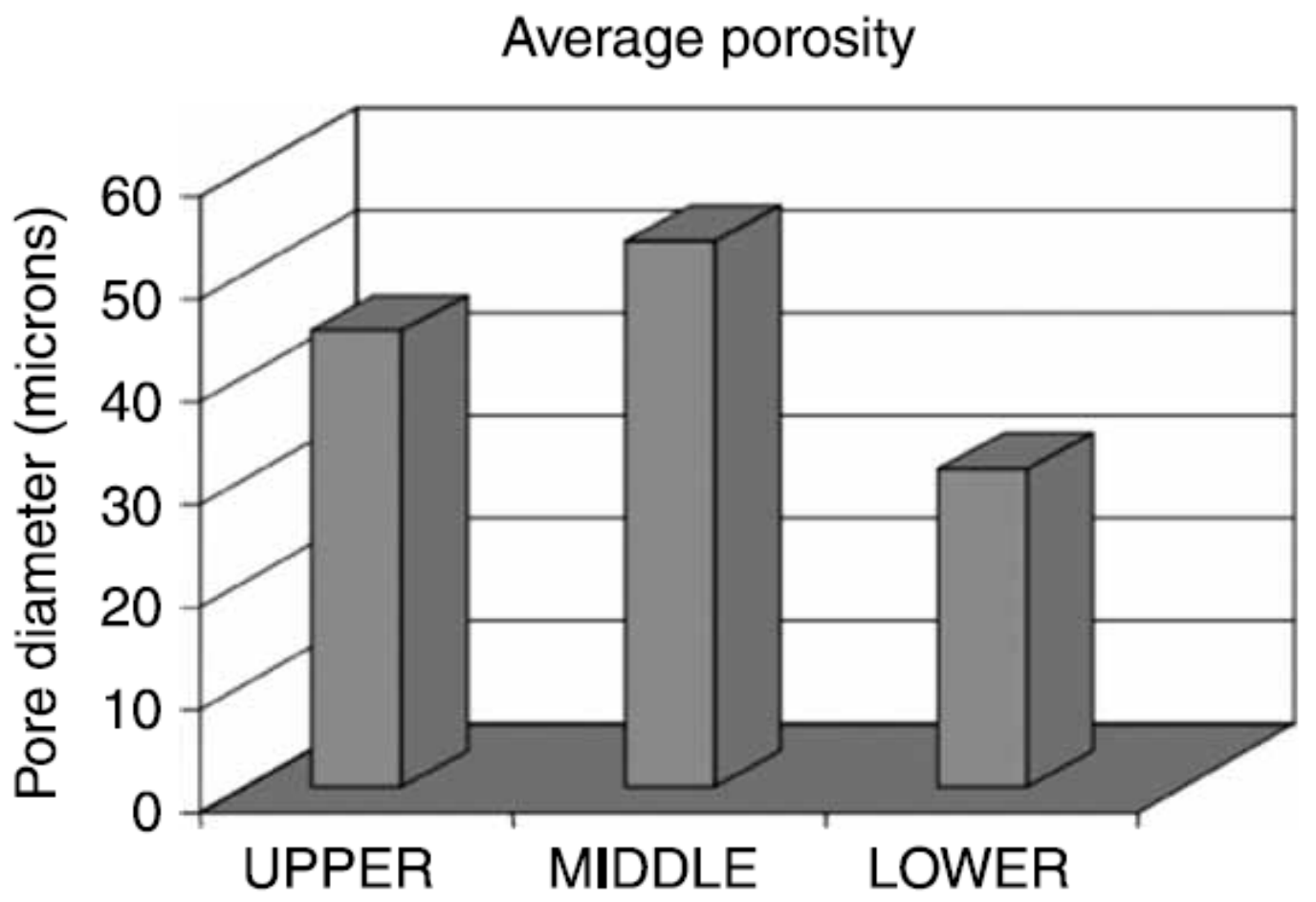

Figure 6. Porosity diameter histogram showing the distribution of pores on three zones of the interface, upper, middle and lower.

The fatigue behaviour of both welded joins without weld bulge or with a softened bulge may be observed through the record of the S-N curve obtained experimentally in this investigation. The points obtained were adjusted using least squares, obtaining the curves shown in Figure 7, which, unlike those presented by Pinho da Cruz ${ }^{20}$, show an adjustment closer to the general fatigue behaviour, both for the aluminium alloys and for the welded joins of these alloys.

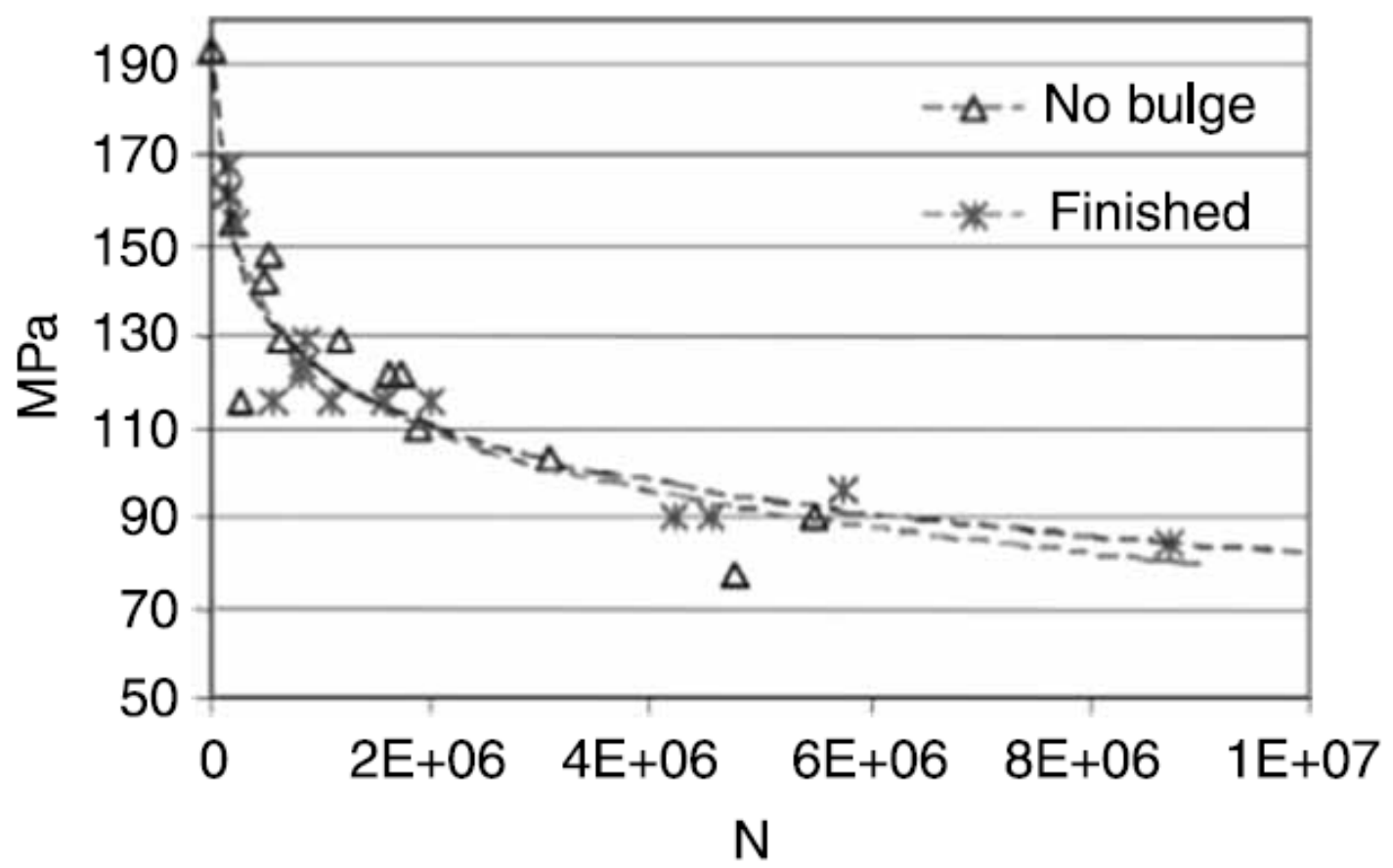

Figure 7. Fatigue curve of welded joins with the bulge finished or removed. 
As can be seen from Figure 7, the total or partial elimination of the weld bulge does not represent a significant change in the welded joint's fatigue response. However, it is possible to appreciate how the joint without a bulge shows a greater dispersion of results, although a slightly better behaviour at high cycles (above $2-10^{6}$ cycles). This increase, however, is only $3 \%$ and not as reflected in some bibliographic studies, which indicate greater differences.

The similarity between the two behaviours may be due to the fact that the softening of the dihedral angle between the bulge and the base metal significantly reduces the stress concentrating effect of the bulge, in the same way as the elimination of the cracks due to bulge smearing (see Figure 8), perceptibly reducing the difference in fatigue behaviour between the two conditions, elimination or softening of the bulge. Nevertheless, the surface roughness is a determining factor in crack initiation, since it has been observed that the majority of cracks began at the base of the weld bead machining, as may also be appreciated in Figure 9.

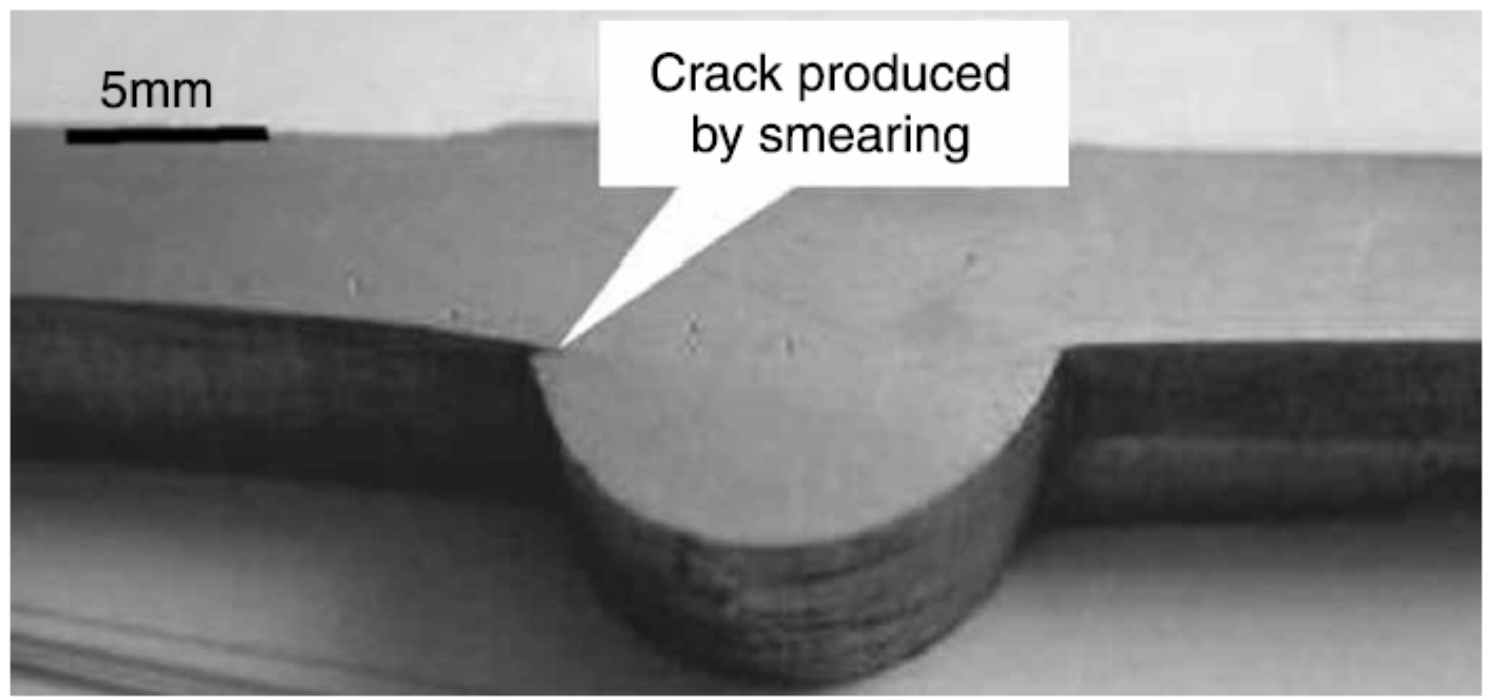

Figure 8. Photograph of a crack produced by the bulge smearing. 


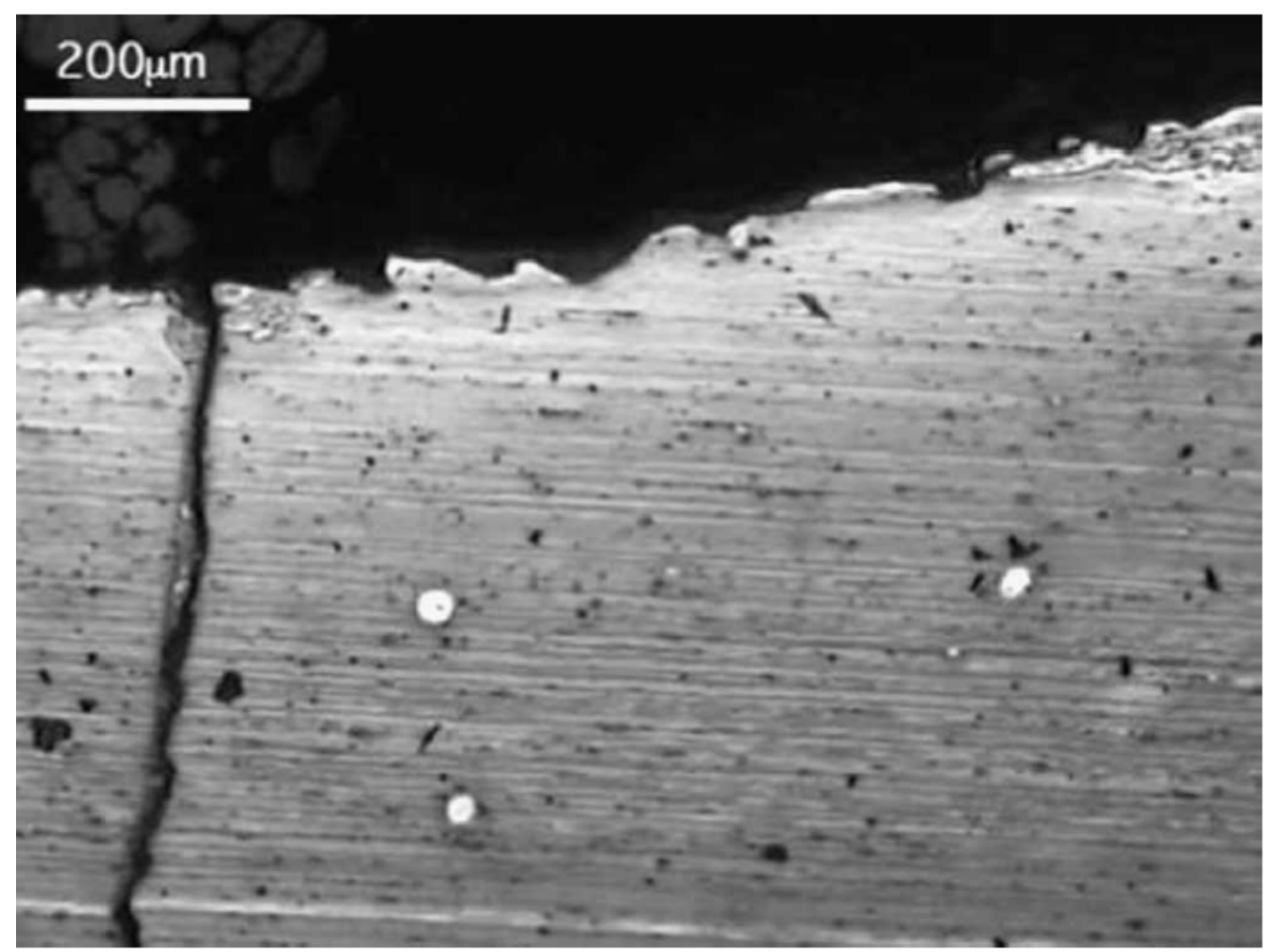

Figure 9. Micrography showing a crack in the HAZ near the base metal-weld interface. Triacid etching.

Nevertheless, on several occasions, it was noted that despite the fact that the crack occurred inside the bead or in the HAZ, in parallel, other cracks inside the HAZ followed, Figure 10, which progressed in parallel to the main crack, at around $5 \mathrm{~mm}$ from the interface. However, this second crack began after the main crack, or at least its growth velocity was less and independent of the preparation of the bulge, from which it may be inferred that both procedures, softening or elimination of the bulge, increase the fatigue life in comparison with welding with an unmodified bulge. 


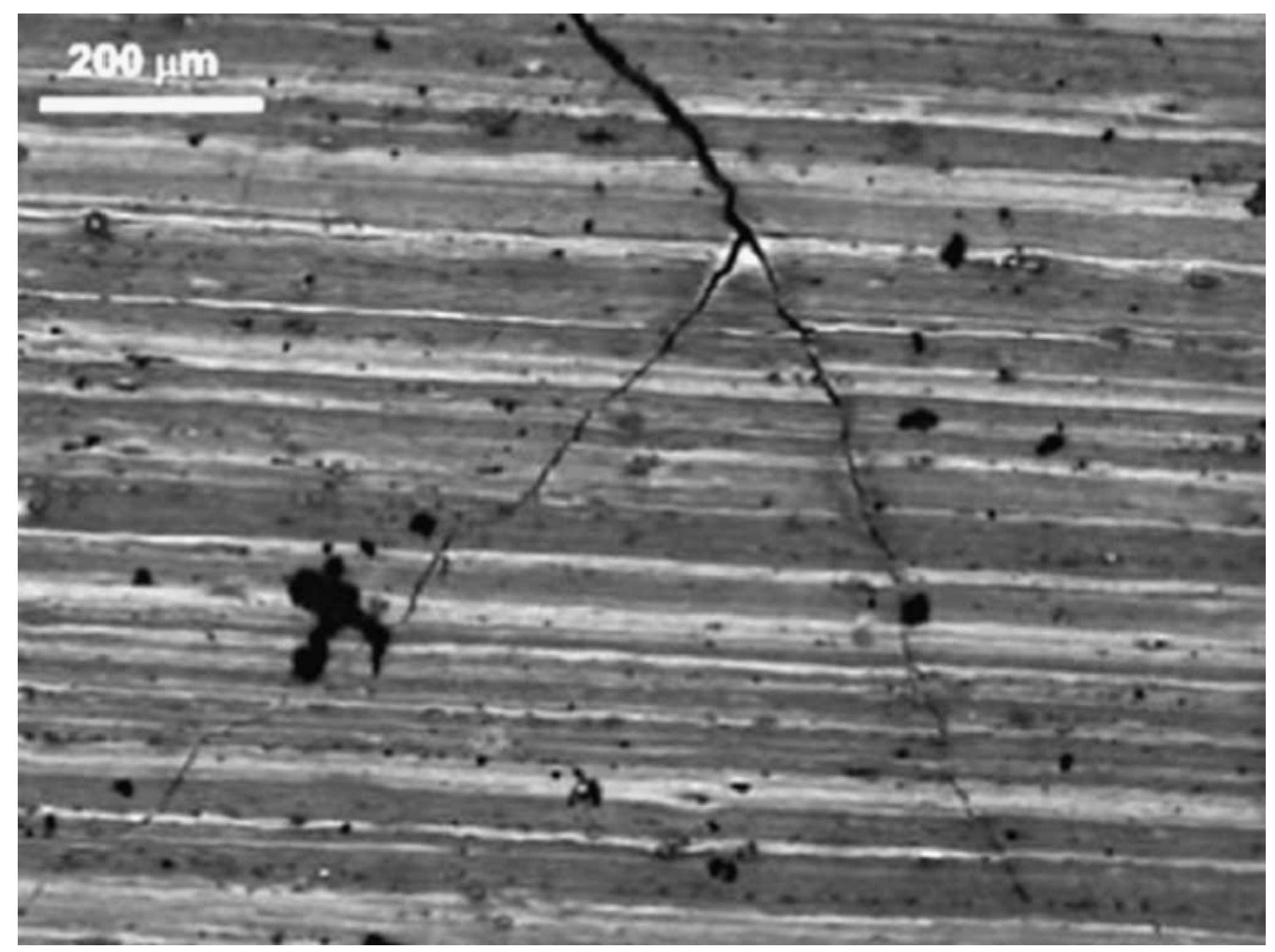

Figure 10. Morphology of a parallel secondary crack. Weck etching.

These parallel cracks may provide a response to the comments of various authors8,9,19 indicating that, some $5 \mathrm{~mm}$ from the corresponding joint, there exists a zone of partial dissolution and ageing with a lowering of resistance.

\section{Conclusions}

Based on the results and observations made, it may be concluded that:

(1) The preparation of the bulge has a decisive influence on the fatigue response of the welded joint, substantially improving resistance.

(2) Surface roughness is the principal element responsible for the fatigue response of the welded joint, perceptibly improving when the bulge is retouched and softened or completely eliminated.

(3) Crack initiation, as might have been expected, occurs in the notches, products of the surface roughness.

(4) Not only is a single crack produced, leading to fracture, but parallel cracks also appear in different zones of the HAZ.

\section{References}

1. Gomez de Salazar JM, Ureña A, Villauriz E, Manzanedo S, Barrena I. Rev Metal Madrid. 1998;34:276-280.

2. Mondolfo LF. Aluminium alloys: structure and properties. Ed. Butterworths, London. 1976. 
3. American society for metals. Aluminium and aluminium alloys. ASM Specialty Handbook, Ed. ASM International, Ohio, EE. UU. 1993.

4. Rodrigo P, Poza P, Utrilla MV, Ureña A. Rev Metal Madrid. 2005;41:298-307.

5. Ryum N. Z. Meta.k.d. 1975;64:377-388.

6. Hagstron J, Sandstrom R. Sci Tech Weld Join. 1997;2: 199-208.

7. Albuquerque JM, Ramos PA, Gomes MA, Cruz C. Rev Metal Madrid. 2005;41:126132.

8. Fu G, Tian F, Wang H. J Mat Proc Tech. 2006;180:216-220.

9. Ma T, Den Ouden G. Mater Sci Eng A. 1999;266:198-204.

10. Bloem CA, Salvador MD, Amigo’ V, Busquets D. Rev Metal Madrid. 2003;39:298303.

11. Atzori B B, Trentadue A. Riv Ital Soldatura. 1975;27: 349-538.

12. Busquets D. Estudio del comportamiento a fatiga de uniones soldadas de aluminio de alta resistencia para su empleo en la industria del transporte. [Study of fatigue behaviour of welded joins in high strength aluminium for their use in the transport industry], Ed. Universidad Politécnica de Valencia, 1987.

13. Zivkovic D, Anzulovic B. Mater Des. 2005;26:247-250.

14. Hwang RY, Chou CP. Scrip Materialia. 1998;38:215-221.

15. Gatto F, Morri D, In: Novara, editor. Fatigue behaviour of some welded joints of aluminium alloys. 1979.

16. Ko"hler W. Proceedings of the 2nd International Conference on Aluminium Weldments Munich, Alemania 1982, II.7.

17. Bloem CA, Salvador MD, Amigo' V, Vicente A. Rev Metal Madrid. 2000;36:3339.

18. Su J-Q, Nelson TW, Mishra R, Mahoney M. Acta Materialia. 2003;51:713-729.

19. Lefebvre F, Ganguly S, Sinclair I. Mater Sci Eng A. 2005; 397:338-345.

20. Pinho-Da-Cruz JAM, Ferreira JAM, Costa JDM, Borrego LFP. Thin Wall Struct. 2003;41:389-402. 